\title{
Association between statin therapy and outcomes in critically ill patients: a nested cohort study
}

\author{
Shmeylan A Al Harbi ${ }^{1}$, Hani M Tamim² and Yaseen M Arabi ${ }^{3^{*}}$
}

\begin{abstract}
Background: The effect of statin therapy on mortality in critically ill patients is controversial, with some studies suggesting a benefit and others suggesting no benefit or even potential harm. The objective of this study was to evaluate the association between statin therapy during intensive care unit (ICU) admission and all-cause mortality in critically ill patients.

Methods: This was a nested cohort study within two randomised controlled trials conducted in a tertiary care ICU. All 763 patients who participated in the two trials were included in this study. Of these, 107 patients (14\%) received statins during their ICU stay. The primary endpoint was all-cause ICU and hospital mortality. Secondary endpoints included the development of sepsis and severe sepsis during the ICU stay, the ICU length of stay, the hospital length of stay, and the duration of mechanical ventilation. Multivariate logistic regression was used to adjust for clinically and statistically relevant variables.
\end{abstract}

Results: Statin therapy was associated with a reduction in hospital mortality (adjusted odds ratio [aOR] $=0.60,95 \%$ confidence interval [Cl] 0.36-0.99). Statin therapy was associated with lower hospital mortality in the following groups: patients $>58$ years of age $(\mathrm{aOR}=0.58,95 \% \mathrm{Cl} 0.35-0.97)$, those with an acute physiology and chronic health evaluation (APACHE II) score $>22(\mathrm{aOR}=0.54,95 \% \mathrm{Cl} 0.31-0.96)$, diabetic patients $(\mathrm{aOR}=0.52,95 \% \mathrm{Cl} 0.30$ 0.90 ), patients on vasopressor therapy ( $\mathrm{aOR}=0.53,95 \% \mathrm{Cl} 0.29-0.97$ ), those admitted with severe sepsis ( $\mathrm{aOR}=$ $0.22,95 \% \mathrm{Cl} 0.07-0.66)$, patients with creatinine $\leq 100 \mu \mathrm{mol} / \mathrm{L}(\mathrm{aOR}=0.14,95 \% \mathrm{Cl} 0.04-0.51)$, and patients with GCS $\leq 9(\mathrm{aOR}=0.34,95 \% \mathrm{Cl} 0.17-0.71)$. When stratified by statin dose, the mortality reduction was mainly observed with statin equipotent doses $\geq 40 \mathrm{mg}$ of simvastatin ( $\mathrm{aOR}=0.53,95 \% \mathrm{Cl} 0.28-1.00)$. Mortality reduction was observed with simvastatin ( $\mathrm{aOR}=0.37,95 \% \mathrm{Cl} 0.17-0.81)$ but not with atorvastatin $(\mathrm{aOR}=0.80,95 \% \mathrm{Cl} 0.84-1.46)$. Statin therapy was not associated with a difference in any of the secondary outcomes.

Conclusion: Statin therapy during ICU stay was associated with a reduction in all-cause hospital mortality. This association was especially noted in high-risk subgroups. This potential benefit needs to be validated in a randomised, controlled trial.

\section{Background}

Statins, also known as 3-hydroxy-3-methylglutaryl coenzyme A reductase inhibitors, were first introduced in the late 1980 s as cholesterol-lowering drugs for the prevention of cardiovascular events. However, recent studies have demonstrated a wide variety of statin

\footnotetext{
* Correspondence: yaseenarabi@yahoo.com

${ }^{3}$ Intensive Care Department, Medical Director, Respiratory Services, and Associate Professor, College of Medicine, King Saud bin Abdulaziz University for Health Sciences, King Abdulaziz Medical City, Riyadh, Saudi Arabia Full list of author information is available at the end of the article
}

properties independent of their lipid-lowering ability. These properties, known as pleiotropic effects [1-4], include multiple anti-inflammatory actions, the direct activation of heme oxygenase, direct interference in leucocyte-endothelial interactions, and direct inhibition of major histocompatibility complex class II (MHC II) [5-10].

The effect of statin therapy on mortality in critically ill patients is controversial, with some studies suggesting a benefit and others no benefit or even potential harm [11-17]. These divergent results are probably related to

\section{Biomed Central}


differences in study designs, patient populations $[4,11-14,18,19]$, statin types, and doses $[4,15,17,20]$. Therefore, we sought to evaluate the association of statin therapy during the intensive care unit (ICU) stay with all-cause mortality in critically ill medical surgical patients.

\section{Methods}

\section{Setting}

This study was conducted in a 900-bed tertiary academic medical centre. The adult ICU admits medical, surgical, and trauma patients, and it operates as a closed unit with 24-hr, 7-day onsite coverage by a critical care board of certified intensivists. The nurse-to-patient ratio at the unit is approximately 1:1.2 [21].

\section{Study design}

This was a nested cohort study within two randomised, controlled trials.

The first trial, conducted between January 2004 and March 2006 included 532 patients, compared intensive insulin therapy (IIT) (for patients with a blood glucose level of 4.4-6.1 mmol/L or $80-110 \mathrm{mg} / \mathrm{dl}$ ) to conventional insulin therapy (CIT) (for patients with a blood glucose level of $10-11.1 \mathrm{mmol} / \mathrm{L}$ or $180-200 \mathrm{mg} / \mathrm{dl}$ ) [22]. This trial showed no significant difference in ICU mortality between the IIT and CIT groups (13.5\% vs. $17.1 \%, \mathrm{p}=0.3)$. Hypoglycemia occurred more frequently in the IIT than in the CIT group (28.6\% vs. $3.1 \%$ of patients; $\mathrm{p}<0.0001)$ [22].

The second trial, conducted between February 2006 and January 2008, included 240 patients and assessed the effects on outcomes of permissive underfeeding (a caloric goal of $60-70 \%$ of the calculated requirement) versus target feeding (caloric goal of $90-100 \%$ of the calculated requirement) with either IIT or CIT in critically ill patients [23]. The study found no difference between the two groups in 28 -day mortality ( $18 \%$ vs. $23 \%, \mathrm{p}=$ $0.34)$. However, hospital mortality was lower in the permissive underfeeding compared with the target-feeding group ( $30 \%$ vs. $43 \%, p=0.04)$ [23]. All patients enrolled in the original two trials were included in this study.

\section{Statin therapy}

Statins for critically ill patients were prescribed as part of the medication reconciliation process if they had been prescribed in the pre-ICU period. Occasionally, statin therapy was initiated in the ICU for patients admitted with acute coronary syndrome or stroke. The prescribed dose was at the discretion of the treating physician. Data regarding the use, type (simvastatin or atorvastatin) and dose of statin were collected from the hospital information system. Doses of atorvastatin were converted into the equivalent dose of simvastatin at a atorvastatin: simvastatin ratio of 1:2.

\section{Data Collection}

Patient outcomes and the following data were retrieved from the two original studies: age, gender, acute physiology and chronic health evaluation (APACHE II) score [24], sequential organ failure assessment (SOFA) score [25], creatinine, platelet count, bilirubin, international normalised ratio (INR), Glasgow coma scale (GCS) score [26], admission category, history of diabetes, need for mechanical ventilation, vasopressor therapy, sepsis, severe sepsis and septic shock and the presence of chronic cardiac, respiratory, renal, hepatic, or immunocompromising diseases, as defined by the APACHE II system [24].

\section{Outcomes}

The primary outcomes were all-cause ICU and hospital mortality. Secondary outcomes included the development of sepsis and severe sepsis during the ICU stay, ICU and hospital length of stay, and the duration of mechanical ventilation. Sepsis and severe sepsis were defined according to the 2001 International Sepsis Definitions Conference [27]. The two trials were approved by the research committee and institutional review board of King Abdulaziz Medical City.

\section{Statistical analysis}

Statistical analyses were performed using Statistical Analysis Software (SAS, release 8, SAS Institute, Cary, NC, 1999). We compared patients who received statins during their ICU admission (statin group) with those who did not (non-statin group). Baseline characteristics and outcome variables were compared using $t$-test for continuous data and Chi-square test for nominal data. To control for any potential confounding effects of baseline characteristics, we used multivariate logistic regression to calculate adjusted odds ratios (aOR) and 95\% confidence intervals $(\mathrm{CI})$ for the association between statin use and outcome. Adjustments were made for clinically relevant variables and for those that showed a statistically significant difference between the two groups at baseline. These variables included age, gender, admission category, APACHE II score, history of diabetes, creatinine, platelets, GCS, and the presence of chronic cardiac, renal, or respiratory diseases. We further examined the dose effects of statins on the primary and secondary outcomes by stratifying patients on the basis of doses equivalent to $<40 \mathrm{mg}$ and $\geq 40 \mathrm{mg}$ of simvastatin. Additionally, we conducted stratified analyses by age, gender, admission category, APACHE II score, history of diabetes, the presence of chronic cardiac problems, vasopressor therapy, sepsis, severe sepsis and septic shock, creatinine, platelet count, bilirubin, INR, GCS, ICU length of stay, mechanical ventilation and type of statin, to detect any change in the association between 
intervention and outcome measures on the basis of any of these factors. Statistical significance was defined as a $\mathrm{p}$ value $\leq 0.05$.

\section{Results}

Of the 763 patients enrolled in the study, 107 (14\%) received statins during their ICU stay, and 656 (86\%) did not. Atorvastatin was prescribed to 63 patients (58.9\%), with doses ranging between 10 and $80 \mathrm{mg} /$ day. Simvastatin was prescribed to 44 patients (41.1\%), with doses ranging between 10 and $40 \mathrm{mg} /$ day. Table $1 \mathrm{com}-$ pares the baseline characteristics of the statin and nonstatin groups. Patients who received statins were older; more likely to be females; diabetic; more likely to have chronic cardiac, renal or respiratory illness; and had higher APACHE II scores.

Table 2 summarises the association between statin therapy and mortality using multivariate analysis adjusting for the selected confounders. Statin therapy was associated with lower all-cause hospital mortality (aOR $=0.60,95 \%$ CI 0.36-0.99). The association between statins and ICU mortality was not statistically significant

Table 1 Baseline characteristics of patients on statin therapy and non-statin therapy

\begin{tabular}{|c|c|c|c|}
\hline & $\begin{array}{c}\text { Statin } \\
(n=107)\end{array}$ & $\begin{array}{l}\text { Non-Statin } \\
(n=656)\end{array}$ & $P$-value \\
\hline Age, mean \pm SD (yrs) & $68.8 \pm 11.0$ & $49.3 \pm 21.7$ & $<0.0001$ \\
\hline Female gender, no. (\%) & $44(41.1)$ & $164(25)$ & 0.0005 \\
\hline APACHE II, mean \pm SD & $27.2 \pm 6.9$ & $23.0 \pm 8.1$ & $<0.0001$ \\
\hline SOFA day 1 , mean \pm SD & $9.3 \pm 3.2$ & $9.2 \pm 3.5$ & 0.92 \\
\hline $\begin{array}{l}\text { Creatinine, mean } \pm S D \text {, } \\
\mu \mathrm{mol} / L^{*}\end{array}$ & $200.8 \pm 152.6$ & $152.3 \pm 152.1$ & 0.002 \\
\hline Platelets, mean $\pm \mathrm{SD}, \times 10^{9} / \mathrm{L}$ & $270.7 \pm 117.8$ & $193.3 \pm 123.3$ & 0.0001 \\
\hline Bilirubin, mean $\pm \mathrm{SD}, \mu \mathrm{mol} / \mathrm{l}$ & $26.4 \pm 63.6$ & $31.6 \pm 55.2$ & 0.50 \\
\hline INR, mean $\pm \mathrm{SD}$ & $1.5 \pm 0.7$ & $1.5 \pm 0.9$ & 0.72 \\
\hline $\mathrm{GCS}$, mean $\pm \mathrm{SD}$ & $9.4 \pm 4.5$ & $8.5 \pm 4.0$ & 0.05 \\
\hline \multicolumn{4}{|l|}{ ICU admission category, no. (\%) } \\
\hline Postoperative & $4(3.7)$ & $119(18.1)$ & 0.0002 \\
\hline Nonoperative & $103(96.3)$ & $537(81.9)$ & \\
\hline History of diabetes, no. (\%) & $84(78.5)$ & $219(33.4)$ & $<0.0001$ \\
\hline Mechanically ventilated, no. (\%) & $92(86.0)$ & $591(90.1)$ & 0.20 \\
\hline Vasopressors, no. (\%) & $73(68.2)$ & $423(64.5)$ & 0.45 \\
\hline Sepsis, no. (\%) & $28(26.2)$ & $166(25.3)$ & 0.85 \\
\hline Severe sepsis, no. (\%) & $26(24.3)$ & $207(31.5)$ & 0.13 \\
\hline Chronic respiratory, no. (\%) & $33(30.8)$ & $124(18.9)$ & 0.005 \\
\hline Chronic cardiac, no. (\%) & $54(50.5)$ & $103(15.7)$ & $<0.0001$ \\
\hline Chronic renal, no. (\%) & $29(27.1)$ & $74(11.3)$ & $<0.0001$ \\
\hline Chronic liver, no. (\%) & $4(3.7)$ & $50(7.6)$ & 0.15 \\
\hline $\begin{array}{l}\text { Chronic immunocompromised, } \\
\text { no. (\%) }\end{array}$ & $10(9.4)$ & $56(8.5)$ & 0.78 \\
\hline
\end{tabular}

SD: standard deviation, APACHE II: Acute physiology and chronic health evaluation II; SOFA: Sequential organ failure assessment; INR: International normalised ratio; GCS: Glasgow coma scale.

*To convert units to $\mathrm{mg} / \mathrm{dl}$, divide by 88.4 for creatinine and 17.1 for bilirubin
$(\mathrm{aOR}=0.84,95 \%$ CI $0.47-1.51)$. When stratified by statin dose, a significant reduction in hospital mortality was observed with doses of $\geq 40 \mathrm{mg}(\mathrm{aOR}=0.53,95 \%$ CI 0.28-1.00).

Table 3 shows the association between statin therapy and all-cause hospital mortality stratified by different characteristics using multivariate analysis. Statin therapy was associated with lower hospital mortality in patients older than 58 years $(\mathrm{aOR}=0.58,95 \%$ CI $0.35-0.97)$, those with an APACHE II score $>22(\mathrm{aOR}=0.54,95 \%$ CI 0.31-0.96), diabetic patients ( $\mathrm{aOR}=0.52,95 \% \mathrm{CI}$ $0.30-0.90$ ), patients on vasopressor therapy ( $\mathrm{aOR}=0.53$, 95\% CI $0.29-0.97$ ), those with creatinine $\leq 100 \mu \mathrm{mol} / \mathrm{L}$ $(\mathrm{aOR}=0.14,95 \% \mathrm{CI} 0.04-0.51)$, patients with severe sepsis ( $\mathrm{aOR}=0.22,95 \% \mathrm{CI} 0.07-0.66$ ), and patients with a GCS $\leq 9(\mathrm{aOR}=0.34,95 \% \mathrm{CI} 0.17-0.71)$. When stratified by statin type, statistically significant association with lower mortality was observed by simvastatin (aOR $=0.37,95 \%$ CI 0.17-0.81), but not with atorvastatin.

There was no significant association between statin use and the development of sepsis or severe sepsis and septic shock, ICU and hospital length of stay, or the duration of mechanical ventilation (Table 4).

\section{Discussion}

Our study demonstrates that statin therapy in critically ill patients is associated with lower hospital mortality. This effect was observed predominantly in elderly patients, diabetics, patients with higher severity of illness, with a low GCS, patients on vasopressors, with severe sepsis, and those on simvastatin.

Several studies have shown favourable effects of statin therapy on outcomes in critically ill patients. Liappies et al. retrospectively reviewed patients with documented bacteraemia and found that statin therapy was associated with a significant reduction in overall hospital mortality and infection rates (11). Almog et al. found that prior statin therapy was associated with a reduction in severe sepsis and the incidence of ICU admission [12]. Kruger et al. studied a cohort of bacteraemia patients and found a significantly lower incidence of mortality and bacteraemia-related mortality with statin therapy [13]. Mortensen et al. found that statin therapy before ICU admission was associated with a decreased 30-day mortality [20]. A recent systematic review examined the effect of statins on mortality in patients with infection and/or sepsis. The review included a total of 20 studies, with 18 cohort studies (12 retrospective and 6 prospective), 1 matched cohort study with 2 case-controlled studies, and 1 randomised, controlled trial. The review demonstrated a protective effect of statin therapy for various infection-related outcomes compared with placebo in patients with sepsis and/or other infections [28]. These studies are in concordance with ours, which 
Table 2 Association between statin use and primary outcomes compared with the non-statin group using adjusted analyses

\begin{tabular}{|c|c|c|c|c|c|}
\hline & $\begin{array}{c}\text { Statin } \\
\mathrm{n}=107\end{array}$ & $\begin{array}{c}\text { Non-statin } \\
n=656\end{array}$ & Adjusted odds ratio (aOR) ${ }^{a}$ & 95\% confidence interval & $P$-value \\
\hline ICU mortality, no. (\%) & $19 / 107(17.8)$ & $108 / 656(16.5)$ & 0.84 & $(0.47-1.51)$ & 0.56 \\
\hline Dose $<40 \mathrm{mg}$ & $7 / 47(14.9)$ & $108 / 656(16.5)$ & 0.67 & $(0.28-1.63)$ & 0.43 \\
\hline Dose $\geq 40 \mathrm{mg}$ & $12 / 60(20.0)$ & $108 / 656(16.5)$ & 0.97 & $(0.48-1.99)$ & 0.98 \\
\hline Hospital mortality, no. (\%) & 42/107 (39.3) & $200 / 656(30.5)$ & 0.60 & $(0.36-0.99)$ & 0.05 \\
\hline Dose $<40 \mathrm{mg}$ & 19/47 (40.4) & $200 / 656(30.5)$ & 0.69 & $(0.35-1.40)$ & 0.30 \\
\hline Dose $\geq 40 \mathrm{mg}$ & 23/60 (38.3) & 200/656 (30.5) & 0.53 & $(0.28-1.00)$ & 0.05 \\
\hline
\end{tabular}

Variables entered initially in the stepwise regression model including age, gender, admission category, APACHE II score, history of diabetes, creatinine, platelets, $\mathrm{GCS}, \mathrm{PaO}_{2} / \mathrm{FiO}_{2}$, and chronic cardiac, renal, and respiratory diseases.

demonstrated a significant reduction in mortality with statin therapy in critically ill patients and patients with sepsis, severe sepsis and septic shock. The effect was primarily observed with higher doses of statins.

In contrast, some investigators have not found statin therapy to be beneficial. Fernandez et al. analysed data from 438 patients receiving mechanical ventilation for more than $96 \mathrm{hr}$ and found that hospital mortality was significantly higher with statin therapy (61\% vs. $42 \%)$, even after adjusting for APACHE II predicted risk (observed/expected ratio 1.53 vs. 1.17). In a populationbased study of community-acquired pneumonia, Majumdar et al. found that statin users were less likely to die or to be admitted to the ICU than non-users (50/ $325[15 \%]$ vs. 574/3090 [19\%], respectively; OR 0.80, p = 0.15). However, after a more complete adjustment for confounding factors, the OR changed from potential benefit $(0.78$, adjusted for age and sex) to potential harm (1.10, fully adjusted, including propensity scores, 95\% CI 0.76-1.60). This disagreement with the findings of our study may be explained by differences in illness severity. As subjects of a population-based study, the patients of Majumdar et al. were relatively healthy users [15] compared with our population. Additionally, it remains unclear whether these findings, which were observed in patients with community-acquired pneumonia, are applicable to all critically ill patients. Yang et al. conducted a retrospective study and found no difference in mortality between the two groups, despite the presence in patients in the statin group of less organ dysfunction, lower APACHE II scores, less inotropic support, and less shock [16]. The lack of benefit observed in these studies might be related to differences in the patient disease mix, severity of illness, or statin type/dose.

Our study demonstrated a mortality reduction in older patients and those with more severity of illness. This result confirms what other previous studies have shown. Dobesh et al. evaluated patients over the age of 40 with severe sepsis who were exposed to statins before and/or during hospitalisation. The mean APACHE II score in the statin group was 26. Patients in the statin group showed a lower mortality compared with the no statin group ( $31.7 \%$ vs. $48.4 \%$; $\mathrm{p}=0.04)$, and this effect was more evident in older patients and those with higher APACHE II score [18]. Schmidt et al. evaluated statin therapy in patients with multi-organ dysfunction and a mean APACHE II score $\geq 30$. The study demonstrated that 28-day mortality was significantly lower in the statin group compared with the no statin group (33\% vs. $53 \%$; $=0.03$ ).

We observed a mortality reduction with simvastatin but not atorvastatin. A similar finding was noted by Christensen et al. [19]. This result might be related to the higher lipophilicity of simvastatin, which enables it to better penetrate cells [29]. However, large sample size is required to confirm these findings.

The observed beneficial effects of statins on diabetic patients, patients with chronic cardiovascular disease and those with low GCS (a surrogate for neurologic disease) are consistent with its reported benefits in acute myocardial infarction and acute stroke [30,31]. Our results are also consistent with the findings of a population-based study by Hackam et al., who found that statin use in patients with atherosclerosis was associated with a reduced risk of subsequent sepsis [32].

Our findings confirm the need for randomised, controlled trials to verify the relationship between statin therapy and the observed outcomes. Other issues still require resolution, including the dose-effect relationship, whether the mechanism of action is related to the pleiotropic or lipid-lowering effect of statins, and whether the observed effect is a class effect or an individual statin effect [33]. We hope that the ongoing clinical trials in patients with sepsis, septic shock, ventilator-associated pneumonia, and influenza, as well as the trials investigating the prevention of acute lung injury and adult respiratory distress syndrome will help address these questions [34-38].

The findings of our study must be interpreted in the light of its strengths and weaknesses. The strengths include being a nested cohort within randomised 
Table 3 Association between statin therapy and hospital mortality, stratified by different relevant characteristics

\begin{tabular}{|c|c|c|c|c|c|}
\hline & $\begin{array}{c}\text { Statin } \\
\mathrm{n}=107\end{array}$ & $\begin{array}{c}\text { Non-statin } \\
\mathrm{n}=656\end{array}$ & Adjusted odds ratio (aOR) & 95\% confidence interval & $P$-value \\
\hline Hospital mortality, no. (\%) & $42 / 107(39.3)$ & $200 / 656(30.5)$ & 0.60 & $(0.36-0.99)$ & 0.05 \\
\hline \multicolumn{6}{|l|}{ Stratified by age, no. (\%) } \\
\hline$\leq 58 \mathrm{yrs}$ & $6 / 14(42.9)$ & $62 / 374(16.6)$ & 0.73 & $(0.19-2.81)$ & 0.64 \\
\hline$>58 \mathrm{yrs}$ & 36/93 (38.7) & $138 / 282(49.0)$ & 0.58 & $(0.35-0.97)$ & 0.04 \\
\hline \multicolumn{6}{|l|}{ Gender, no. (\%) } \\
\hline Male & 21/63 (33.3) & $126 / 492(25.6)$ & 0.56 & $(0.29-1.08)$ & 0.08 \\
\hline Female & $21 / 44(47.7)$ & $74 / 164(45.0)$ & 0.74 & $(0.35-1.58)$ & 0.43 \\
\hline \multicolumn{6}{|l|}{ Admission category, no. (\%) } \\
\hline Postoperative & $1 / 4(25.0)$ & 19/119 (16.0) & 0.75 & $(0.04-14.82)$ & 0.85 \\
\hline Nonoperative & $41 / 103(40.0)$ & 181/537 (34.0) & 0.62 & $(0.34-1.03)$ & 0.06 \\
\hline \multicolumn{6}{|l|}{ APACHE ॥, no. (\%) } \\
\hline APACHE $\leq 22$ & $8 / 33(24.2)$ & $53 / 370(14.3)$ & 0.77 & $(0.27-2.21)$ & 0.63 \\
\hline APACHE $>22$ & $34 / 74(46.0)$ & $147 / 286(51.4)$ & 0.54 & $(0.31-0.96)$ & 0.03 \\
\hline \multicolumn{6}{|l|}{ SOFA, no. (\%) } \\
\hline$\leq 9$ & $13 / 58(22.4)$ & 63/346 (18.2) & 0.55 & $(0.26-1.17)$ & 0.12 \\
\hline$>9$ & 29/49 (59.1) & $137 / 310(44.2)$ & 0.73 & $(0.36-1.48)$ & 0.38 \\
\hline \multicolumn{6}{|l|}{ History of diabetes, no. (\%) } \\
\hline Yes & $31 / 84(37.0)$ & $106 / 209(48.4)$ & 0.52 & $(0.30-0.90)$ & 0.02 \\
\hline No & $11 / 23(47.8)$ & $94 / 437(21.5)$ & 1.31 & $(0.49-3.54)$ & 0.59 \\
\hline \multicolumn{6}{|c|}{ History of cardiovascular, no. (\%) } \\
\hline Yes & 23/54 (42.6) & $58 / 103(56.3)$ & 0.59 & $(0.3-1.2)$ & 0.13 \\
\hline No & 19/53 (35.9) & $142 / 553(25.7)$ & 0.52 & $(0.27-1)$ & 0.06 \\
\hline \multicolumn{6}{|l|}{ Vasopressor therapy, no. (\%) } \\
\hline Yes & $31 / 73(42.5)$ & $151 / 423(35.7)$ & 0.53 & $(0.29-0.97)$ & 0.04 \\
\hline No & 23/34 (67.7) & 184/233 (79.0) & 0.92 & $(0.37-2.25)$ & 0.84 \\
\hline \multicolumn{6}{|l|}{ Sepsis, no. (\%) } \\
\hline Yes & $12 / 28(43.0)$ & $88 / 166(53.0)$ & 0.64 & $(0.26-1.58)$ & 0.33 \\
\hline No & 30/79 (38.0) & $112 / 490(23.0)$ & 0.72 & $(0.41-1.28)$ & 0.26 \\
\hline \multicolumn{6}{|c|}{ Severe sepsis and septic shock no. (\%) } \\
\hline Yes & $14 / 26(53.9)$ & $84 / 207(40.6)$ & 0.22 & $(0.07-0.66$ & 0.007 \\
\hline No & 28/81 (34.6) & $116 / 449(25.7)$ & 0.78 & $(0.45-1.37)$ & 0.38 \\
\hline \multicolumn{6}{|l|}{ Creatinine, no. (\%) } \\
\hline$\leq 100 \mu \mathrm{mol} / \mathrm{L}$ & $4 / 26(15.4)$ & 70/351 (20.0) & 0.14 & $(0.04-0.51)$ & 0.002 \\
\hline$>100 \mu \mathrm{mol} / \mathrm{L}$ & 38/81 (47.0) & 130/305 (43.0) & 1.01 & $(0.58-1.77)$ & 0.96 \\
\hline \multicolumn{6}{|l|}{ Platelets, no. (\%) } \\
\hline$\leq 180$ & $12 / 25(48.0)$ & $125 / 358(35.0)$ & 0.62 & $(0.24-1.62)$ & 0.33 \\
\hline$>180$ & 30/82 (36.6) & 75/298 (25.2) & 0.78 & $(0.43-1.42)$ & 0.42 \\
\hline \multicolumn{6}{|l|}{ Bilirubin, no. (\%) } \\
\hline$\leq 16 \mu \mathrm{mol} / \mathrm{L}$ & 10/38 (26.3) & $54 / 212(25.5)$ & 0.49 & $(0.21-1.20)$ & 0.11 \\
\hline$>16 \mu \mathrm{mol} / \mathrm{L}$ & $10 / 22(45.5)$ & 73/223 (32.7) & 0.67 & $(0.23-1.97)$ & 0.47 \\
\hline \multicolumn{6}{|l|}{ INR, no. (\%) } \\
\hline$\leq 1.2$ & 20/59 (34.0) & 68/312 (21.8) & 0.79 & $(0.40-1.58)$ & 0.51 \\
\hline$>1.2$ & 22/48 (45.8) & $132 / 344(38.4)$ & 0.53 & $(0.26-1.09)$ & 0.09 \\
\hline \multicolumn{6}{|l|}{ GCS, no. (\%) } \\
\hline$\leq 9$ & 19/50 (38.0) & $114 / 364(31.3)$ & 0.34 & $(0.17-0.71)$ & 0.004 \\
\hline$>9$ & 23/57 (40.4) & $86 / 292(29.5)$ & 092 & $(0.46-1.85)$ & 0.81 \\
\hline \multicolumn{6}{|l|}{ Length of stay, no. (\%) } \\
\hline$\leq 5$ days & 4/39 (10.3) & $32 / 192(16.7)$ & 0.40 & $(0.13-1.28)$ & 0.12 \\
\hline$>5$ days & 38/68 (55.9) & $168 / 464(36.2)$ & 0.63 & $(0.34-1.19)$ & 0.16 \\
\hline \multicolumn{6}{|c|}{ Mechanical ventilation, no. (\%) } \\
\hline Yes & 40/92 (43.5) & 183/591 (31.0) & 0.66 & $(0.34-1.10)$ & 0.11 \\
\hline
\end{tabular}


Table 3 Association between statin therapy and hospital mortality, stratified by different relevant characteristics (Continued)

\begin{tabular}{|c|c|c|c|c|c|}
\hline No & 2/15 (13.3) & 17/65 (26.2) & 0.75 & $(0.09-6.43)$ & 0.79 \\
\hline Simvastatin, no. (\%) & $12 / 44(27.3)$ & 200/656 (30.5) & 0.37 & $(0.17-0.81)$ & 0.01 \\
\hline Atorvastatin, no. (\%) & $30 / 63(47.6)$ & 200/656 (30.5) & 0.80 & $(0.84-1.46)$ & 0.47 \\
\hline
\end{tabular}

APACHE II: Acute physiology and chronic health evaluation II; SOFA: Sequential organ failure assessment; INR: International normalised ratio; GCS: Glasgow coma scale.

*To convert units to $\mathrm{mg} / \mathrm{dl}$, divide by 88.4 for creatinine and 17.1 for bilirubin

Table 4 Association between statin use and outcomes stratified by statin dose

\begin{tabular}{|c|c|c|c|c|c|}
\hline & $\begin{array}{c}\text { Statin therapy } \mathrm{n}= \\
107\end{array}$ & $\begin{array}{c}\text { Non-statin therapy } \mathrm{n}= \\
656\end{array}$ & $\begin{array}{l}\text { Adjusted odds ratio } \\
(\mathrm{aOR})^{\mathrm{a}}\end{array}$ & $\begin{array}{l}95 \% \text { confidence } \\
\text { interval }\end{array}$ & $\begin{array}{c}P- \\
\text { value }\end{array}$ \\
\hline Sepsis, no.\% & $32 / 107(29.9)$ & $280 / 656(42.7)$ & 0.84 & $(0.51-1.37)$ & 0.49 \\
\hline Dose $<40 \mathrm{mg}$ & $16 / 47(34.0)$ & $280 / 656(42.7)$ & 1.11 & $(0.57-2.20)$ & 0.74 \\
\hline Dose $\geq 40 \mathrm{mg}$ & $16 / 60(25.7)$ & 280/656 (42.7) & 0.67 & $(0.36-1.30)$ & 0.22 \\
\hline Severe sepsis, no. \% & 26/107 (24.3) & 207/656 (31.6) & 0.87 & $(0.51-1.50)$ & 0.60 \\
\hline Dose $<40 \mathrm{mg}$ & $11 / 47(23.4)$ & 207/656 (31.6) & 0.88 & $(0.42-1.90)$ & 0.74 \\
\hline Dose $\geq 40 \mathrm{mg}$ & $15 / 60(25.0)$ & 207/656 (31.6) & 0.85 & $(0.44-1.65)$ & 0.64 \\
\hline ICU LOS, mean $\pm S D$, days & $10.2 \pm 12.7$ & $11.3 \pm 10.6$ & * & * & 0.33 \\
\hline $\begin{array}{l}\text { Hospital LOS, mean } \pm S D \text {, } \\
\text { days }\end{array}$ & $67.6 \pm 118.1$ & $58.6 \pm 81.4$ & * & * & 0.37 \\
\hline$M V D$, mean $\pm S D$, days & $9.0 \pm 11.9$ & $10.1 \pm 10.3$ & * & * & 0.33 \\
\hline
\end{tabular}

Variables entered initially in the stepwise regression model including age, gender, admission category, APACHE II, history of diabetes, creatinine, platelets, GCS, and chronic cardiac, renal, and respiratory diseases.

controlled trials with prospective data collection. Among the limitations of our study are its monocenter nature, its post-hoc design, and the lack of data on the duration of statin therapy prior to ICU admission, lipid profile, and statin side effects. Because of the observational nature of the study, there were imbalances at baseline between the statin and non-statin groups. However, we have adjusted for these imbalances using multivariate analysis.

\section{Conclusion}

Our study demonstrated that statin therapy during ICU admission was associated with lower hospital mortality, particularly among elderly patients, diabetics, patients with high APACHE II and low GCS, those on vasopressors, and those on simvastatin. In addition, using doses greater than $40 \mathrm{mg}$ per day was associated with lower hospital mortality. Further randomised, controlled trials are needed to confirm these findings.

\section{Acknowledgements}

None

\section{Author details}

'Intensive Care Department, King Abdulaziz Medical City, Riyadh, Saudi Arabia. ${ }^{2}$ Epidemiology and Biostatistics, College of Medicine, King Saud bin Abdulaziz University for Health Sciences, King Abdulaziz Medical City, Riyadh, Saudi Arabia. Intensive Care Department, Medical Director, Respiratory Services, and Associate Professor, College of Medicine, King Saud bin Abdulaziz University for Health Sciences, King Abdulaziz Medical City, Riyadh, Saudi Arabia.

\section{Authors' contributions}

SAA: Had full access to all data in the study and takes full responsibility for the data, conception and design, participated in the data acquisition, analysis and interpretation, and drafted the manuscript; HMT: Conception and design, data analysis and interpretation and critical revision of the manuscript; YMA: Conception and design, statistical analysis, critical revision of the manuscript and overall supervision.

All authors have read and approved the final manuscript for publication.

\section{Competing interests}

The authors declare that they have no competing interests.

Received: 29 March 2011 Accepted: 6 August 2011

Published: 6 August 2011

\section{References}

1. Weitz-Schmidt G: Statins as anti-inflammatory agents. Trends Pharmacol Sci 2002, 23:482-486

2. Blanco-Colio LM, Tunon J, Martin-Ventura JL, Egido J: Anti-inflammatory and immunomodulatory effects of statins. Kidney Int 2003, 63:12-23.

3. Terblanche M, Almog Y, Rosenson RS, Smith TS, Hackman DG: Statins and sepsis: multiple modifications at multiple levels. Lancet Infect Dis 2007, 7:358-368.

4. Martin CP, Talbert RL, Burgess DS, Peters Jl: Effectiveness of statins in reducing the rate of severe sepsis: a retrospective evaluation. Pharmacotherapy 2007, 27:20-26.

5. Weitz-Schmidt G, Welzenbach K, Brinkmann V, Kamata T, Kallen J, Bruns C, Cottens S, Takada Y, Hommel U: Statins selectively inhibit leukocyte function antigen-1 by binding to a novel regulatory integrin site. Nat Med 2001, 7:687-692.

6. Weitz-Schmidt G: Lymphocyte function-associated antigen-1 blockade by statins: molecular basis and biological relevance. Endothelium 2003, 10:43-47.

7. Zingarelli B: Nuclear factor-kappaB. Crit Care Med 2005, 33:S414-416.

8. Falagas ME, Makris GC, Matthaiou DK, Rafailidis PI: Statins for infection and sepsis: a systematic review of the clinical evidence. $J$ Antimicrobial Chemotherapy 2008, 61:774-785. 
9. Kronmann L, Hatfield C, Kronmann K: Statin therapy: not just used to lower cholesterol? Crit Care Nurs, Q 2007, 30:154-160.

10. lijima K, Ouchi Y: Can statins slow the process of vascular calcification? Possibilities of lipid-lowering therapy and pleiotropic effect by statin treatment. Clin Calcium 2010, 20:1719-28.

11. Liappis $A P$, Kan $V L$, Rochester $C G$, Simon GL: The effect of statins on mortality in patients with bacteremia. Clin Infect Dis 2001, 33:1352-1357.

12. Almog Y, Shefer A, Novack V, Maimon N, Barski L, Eizinger M, Friger M, Zeller L, Danon A: Prior statin therapy is associated with a decreased rate of severe sepsis. Circulation 2004, 110:880-885.

13. Kruger P, Fitzsimmons K, Cook D, Jones M, Nimmo G: Statin therapy is associated with fewer deaths in patients with bacteraemia. Intensive Care Med 2006, 32:75-79.

14. Fernandez R, De Pedro VJ, Artigas A: Statin therapy prior to ICU admission: protection against infection or a severity marker? Intensive Care Med 2006, 32:160-164

15. Majumdar SR, McAlister FA, Eurich DT, Padwal RS, Marrie TJ: Statins and outcomes in patients admitted to hospital with community acquired pneumonia: population based prospective cohort study. BMJ 2006, 333:999-1001.

16. Yang KC, Chien JY, Tseng WK, Hsueh PR, Yu CJ, Wu CC: Statins do not improve short-term survival in an oriental population with sepsis. Am $J$ Emerg Med 2007, 25:494-501.

17. Thomsen RW, Hundborg HH, Johnsen SP, Pedersen L, Sorensen HT, Schonherder HC, Lervang hh: Statin use and mortality within 180 days after bacteremia: a population-based cohort study. Crit Care Med 2006, 34:1080-1086.

18. Dobesh PP, Klepser DG, McGuire TR, Morgan CW, Olsen KM: Reduction in mortality associated with statin therapy in patients with severe sepsis. Pharmacotherapy 2009, 29:621-630.

19. Christensen $S$, Thomsen RW, Johansen MB, Pedersen L, Jensen R, Larsen KM, Larsson A, Tonnesen E, Sorensen HR: Preadmission statin use and one-year mortality among patients in intensive care - a cohort study. Crit Care 2010, 14:R29.

20. Mortensen EM, Restrepo MI, Anzueto A, Pugh J: The effect of prior statin use on 30-day mortality for patients hospitalized with communityacquired pneumonia. Respir Res 2005, 6:82.

21. Arabi Y, Alshimemeri A, Taher S: Weekend and weeknight admissions have the same outcome of weekday admissions to an intensive care unit with onsite intensivist coverage. Crit Care Med 2006, 34:605-611.

22. Arabi YM, Dabbagh OC, Tamim HM, Al-Shimemeri AA, Memish ZA, Haddad SH, Syed SJ, Giridhar HR, Rishu AH, Al-Daker MO, Kaahoul Sh, Rritts RK, Sakkijha MH: Intensive versus conventional insulin therapy: a randomized controlled trial in medical and surgical critically ill patients. Crit Care Med 2008, 36:3190-3197.

23. Arabi Y, Tamim H, Shifaat G, Sakkijha M, Al-Dawood A, Al-Sultan M: Permissive Underfeeding Versus Target Feeding in Critically III Patients: Randomized Controlled Trial. Am J Respir Crit Care Med 2009, 179:A2167.

24. Knaus WA, Draper EA, Wagner DP, Zimmerman JE: APACHE II: a severity of disease classification system. Crit Care Med 1985, 13:818-829.

25. Ferreira FL, Bota DP, Bross A, Melot C, Vincent JL: Serial evaluation of the SOFA score to predict outcome in critically ill patients. JAMA 2001, 286:1754-1758

26. Livingston BM, Mackenzie SJ, MacKirdy FN, Howie JC: Should the presedation Glasgow Coma Scale value be used when calculating Acute Physiology and Chronic Health Evaluation scores for sedated patients? Scottish Intensive Care Society Audit Group. Crit Care Med 2000, 28:389-394.

27. Levy MM, Fink MP, Marshall JC, Abraham E, Angus D, Cook D, Cohen J, Opal SM, Vincent JL, Ramsay G: 2001 SCCM/ESICM/ACCP/ATS/SIS International Sepsis Definitions Conference. Crit Care Med 2003, 31:1250-1256.

28. Janda S, Young A, FitzGerald J, Etminan M, Swiston J: The effect of statin on mortality from severe infections and sepsis: A systemic review and meta-analysis. Journal of Critical Care 2010, 25:656.e7-656.e22

29. Dobesh P, Swahn S, Peterson E: Statins in sepsis. Journal of Pharmacy Practice 2010, 1:38-49.

30. Stenestrand $U$, Wallentin $L$ : Early statin treatment following acute myocardial infarction and 1-year survival. JAMA 2001, 285:430-6.

31. Aslanyan S, Weir CJ, Mclnnes GT, Reid JL, Walters MR, Lees KR: Statin administration prior to ischemic stroke onset and survival: exploratory evidence from matched treatment-control study. Eur J Neurol 2005, 12:493-8.

32. Hackam DG, Mamdani M, Li P, Redelmeier DA: Statins and sepsis in patients with cardiovascular disease: a population-based cohort analysis. Lancet 2006, 367:413-418

33. Weant KA, Cook AM: Potential roles for statins in critically ill patients. Pharmacotherapy 2007, 27:1279-1296.

34. Statins for early treatment of sepsis. ClinicalTrials.gov Identifier: NCT00528580. [http://clinicaltrials.gov/show/NCT00528580], Accessed October 17, 2010.

35. Simvastatin in patients with septic shock. ClinicalTrials.gov Identifier: NCT00450840. [http://clinicaltrials.gov/show/NCT00450840], accessed October 17, 2010.

36. Pravastatin and ventilatory associated pneumonia. ClinicalTrials.gov Identifier: NCT00702130. [http://clinicaltrials.gov/show/NCT00702130], Accessed October 17, 2010.

37. Simvastatin effect on the incidence of acute lung injury/adult respiratory distress syndrome. NCT01195428. [http://clinicaltrials.gov/ show/NCT00702130], Accessed October 17, 2010.

38. Statin trial for influenza patients. ClinicalTrials.gov Identifier: NCT00970606. [http://Clinicaltrials.gov/show/NCT00970606], accessed October 17, 2010.

\section{Pre-publication history}

The pre-publication history for this paper can be accessed here: http://www.biomedcentral.com/1472-6904/11/12/prepub

doi:10.1186/1472-6904-11-12

Cite this article as: Al Harbi et al:: Association between statin therapy and outcomes in critically ill patients: a nested cohort study. BMC Clinical Pharmacology 2011 11:12.

\section{Submit your next manuscript to BioMed Central and take full advantage of:}

- Convenient online submission

- Thorough peer review

- No space constraints or color figure charges

- Immediate publication on acceptance

- Inclusion in PubMed, CAS, Scopus and Google Scholar

- Research which is freely available for redistribution

Submit your manuscript at www.biomedcentral.com/submit
C Biomed Central 